\title{
Qual o impacto do Whatsapp em eleições? Uma revisão sistemática (2010-2019)
}

\section{What are the impacts of Whatsapp on elections? A systematic review (2010-2019)}

\author{
Bruno Marques Schaefer \\ Tiago Alexandre Leme Barbosa \\ Sara de Sousa Fernandes Epitácio \\ Roberta Carnelos Resende
}

\section{Resumo}

As eleiçóes brasileiras de 2018 foram marcadas por uma nova forma de se fazer campanhas. Se antes o horário gratuito político eleitoral (HGPE) reforçava a ampliação de coligaçôes e compelia pequenos partidos a serem criativos no uso de seu tempo de rádio e TV, atualmente novos sistemas de tecnologia têm sido utilizados. Este artigo busca compreender de que forma os periódicos têm abordado a temática. O objetivo central é fazer uma revisão sistemática do que foi publicado envolvendo WhatsApp e eleiçóes, no período 2010-2019, em quatro bases de dados: Scielo, Google Scholar, Web of Science e Scopus. O estudo nos permite dizer que os casos analisados e a produção sobre o tema encontraram maior adesáo em países democratizados no contexto da "terceira onda". Quanto à contribuiçáo do aplicativo para o fortalecimento da democracia, as opinióes se dividem entre aqueles que apontam para o perigo do uso de fake news e aqueles que observam no aplicativo uma forma de democratizar o acesso à informaçáo.

\section{Palavras-chave}

Revisão Sistemática; WhatsApp e Eleiçóes; Mídias Sociais; Comunicação Política.

\begin{abstract}
The Brazilian elections of 2018 were marked by a new way of political campaigning. While free political electoral time (HGPE) once reinforced the broadening of coalitions and compelled small parties to be creative in using their radio and TV time, now new technology systems have been heavily used. This article aims to understand how the journals have approached the theme. The main objective is to make a systematic review of publications related to WhatsApp and elections, from 2010 to 2019, in four databases: Scielo, Google Scholar, Web of Science and Scopus. The study allows us to say that the analyzed cases and the production on the theme found greater adherence in democratized countries in the context of the "third wave". Regarding the app's contribution to the strengthening of democracy, opinions are divided between those who point to the danger of using fake news and possible distortions of electoral results and, on the other side, those who observe the app as a way of democratizing access to information.
\end{abstract}

\section{Keywords}

Systematic Review; WhatsApp and Elections; Social Media; Political Communication. 


\section{Introdução}

As eleições presidenciais brasileiras de 2018 ainda estão sendo exploradas por analistas políticos (KRAUSE et al., 2019; SANTOS e TANSCHEIT, 2019). Os elementos obtidos até o momento sinalizam para algumas atipicidades. A polarização entre direita e esquerda, apesar de mantida, não seguiu o padrão consolidado desde as eleições de 1994. O cenário recente da competição eleitoral foi caracterizado pela ausência do PSDB no segundo turno e o protagonismo do PSL no espectro à direita. Os dados sobre o financiamento eleitoral das campanhas presidenciais mostraram que, na história recente do país, essas foram as eleiçôes com o menor valor gasto (KRAUSE et al., 2019). Por outro lado, em decorrência do novo fundo partidário aprovado no final de 2017, houve um favorecimento aos maiores partidos. De acordo com dados apresentados por Nicolau (2019), 51\% (R\$ 763,3 milhóes) do recurso disponível ficou concentrado nas quatro maiores legendas (MDB, PT, PSDB e PP). Já o PSL, partido do candidato vitorioso, recebeu 0,5\% (9,2 milhões) do total de recurso.

A campanha eleitoral de 2018 contou com o uso estratégico de redes sociais como forma de ampliar a interação entre partidos/candidatos e eleitores. A utilização do aplicativo WhatsApp apareceu como um diferencial do pleito. Em termos teóricos, as competiçóes eleitorais e mesmo o comportamento dos partidos variam de acordo com os avanços tecnológicos (KIRCHHEIMER, 1966; TAPSELL, 2018; SANTOS e TANSCHEIT, 2019; KRAUSE et al., 2019). A literatura sobre mídia e comunicação política se ocupa dos mais variados meios de comunicação disponíveis: jornais, TV, rádio, redes sociais ${ }^{1}$ e, recentemente, o WhatsApp. Esses vários meios de comunicação foram estudados por profissionais das mais variadas áreas. Mais do que relacionar toda essa vasta literatura, o nosso objetivo é identificar os trabalhos que tratam de responder à questão: como o WhatsApp impacta na competição eleitoral?

O WhatsApp surgiu em 2009, foi posteriormente comprado pelo Facebook e atualmente opera em mais de 180 países, com mais de 1,5 bilhão de usuários ativos (WHATSAPP, 2019). Analisamos os trabalhos que têm por objeto de estudo o seu uso em eleiçôes. Por meio da técnica de revisão sistemática (RS), selecionamos 26 artigos científicos (working papers e textos em periódicos) publicados entre 2010 e 2018. Como estudo exploratório, buscamos analisar quais são as bases de dados mobilizadas por esses trabalhos (se primárias ou secundárias), os países em questão, os

\footnotetext{
${ }^{1}$ Aqui nos referimos a redes sociais localizadas no ambiente virtual (Web).
} 
alcances das pesquisas, desenhos metodológicos, e, em síntese, o que tem sido apreendido do uso desse aplicativo em eleiçóes. Encontramos, nos trabalhos analisados, evidências do impacto do WhatsApp sobre a competição eleitoral com variaçôes no tamanho desse efeito, principalmente quando se leva em conta os países que são analisados.

O texto está dividido em quatro seções. Na primeira parte, apresentamos um breve apanhado sobre o que é a revisão sistemática. Na sequência, indicamos os procedimentos da pesquisa e o nosso banco de dados. A terceira parte é dedicada à análise dos dados coletados, e, por fim, tecemos algumas consideraçóes sobre a literatura dedicada à temática e o seu estado da arte.

\section{O que é revisão sistemática?}

Autores que advogam a técnica de RS nas Ciências Sociais, com frequência, fazem menção ao fato de tal técnica não ser amplamente usada na área, e, em específico, na Ciência Política (DACOMBE, 2017). Os textos dedicados à apresentação desse método de trabalho, no geral, giram em torno de alguns eixos: i) as vantagens da técnica e defesa do seu uso (DACOMBE, 2017; FIGUEIREDO FILHO et al., 2014); ii) seus limites (PETTICREW, 2001); iii) manuais para suas realizaçôes (DENYER e TRANFIELD, 2009; COOPER, 2010); e, propriamente, iv) as aplicações empíricas do método (SAMPAIO e FIGUEIREDO FILHO, 2019; GROLLA e NISHIJIMA, 2019).

Apesar de um dos primeiros trabalhos sobre a revisão sistemática ser da área da Educação (GLASS, 1976), pesquisadores que debatem esse procedimento lembram que ele é amplamente empregado na área da Saúde (DACOMBE, 2017). De acordo com os defensores da RS, essa técnica: "[...] have been an accepted (perhaps the accepted) method of research synthesis in the clinical and health sciences" (DACOMBE, 2017, p. 1). A RS é diferente de outras formas de revisão da literatura usualmente empregadas nas Ciências Humanas, tais como o ensaio teórico ou os trabalhos de estado da arte. Resumidamente, uma possível definição para a RS seria que "[...] [it] is a method of locating, appraising, and synthesising evidence" (PETTICREW, 2001, p. 98), ou seja, nesse tipo de trabalho, o objeto de estudo são os artigos, teses e dissertaçôes produzidos por um determinado campo de estudos. Além disso, com esse esquema de trabalho, se torna possível colocar questóes novas para dados antigos (GLASS, 1976).

A defesa da RS e de outras técnicas mais sistematizadas de revisão bibliográfica, como a meta-análise e a revisão de pesquisa, se dá igualmente pelo fato 
de que, com critérios objetivos, o viés do pesquisador tende a ser diminuído. O ensaio narrativo literário, ou os textos sobre estado da arte, teriam em maior ou menor medida o problema do viés na seleção de quais textos são representativos de um determinado campo de estudos. A escolha dos trabalhos significativos de um determinado campo do conhecimento esbarraria nos próprios conhecimentos que o pesquisador detém sobre ele. Em termos estatísticos, esse método de trabalho se assemelharia aos casos de amostra por conveniência (FIGUEIREDO FILHO et al., 2014).

Com a RS, no entanto, torna-se possível a própria replicabilidade do trabalho empreendido. À medida que os pesquisadores utilizam adequadamente os protocolos, aumenta-se a transparência da pesquisa. Replicabilidade e transparência, nesse sentido, são alguns dos ganhos no emprego da técnica. A utilização da RS também se dá pelas vantagens nas descobertas de lacunas de um campo de estudos e mesmo no aprimoramento do próprio conhecimento das relaçóes que existem entre variáveis. Para Petticrew e Roberts (2006), um exemplo disso seria o caso da relação entre vitamina $\mathrm{C}$ e gripe. Os autores lembram como uma revisão sistemática empreendida por um grupo de pesquisadores mudou o que se sabia sobre a relação do consumo de Vitamina C e gripe. Por meio da revisão sistemática, pesquisadores observaram que os resultados das pesquisas não sinalizavam para um efeito positivo entre o consumo da Vitamina $\mathrm{C}$ e a prevenção de gripe, contrariando, assim, o que se afirmava sobre o tema.

De acordo com Petticrew (2001), a RS pode ser utilizada por diversas áreas conforme o próprio título do artigo do autor, ela poderia ser feita da Astronomia até a Zoologia. Com temas relacionados à Ciência Política, temos, recentemente, as revisôes de Sampaio e Figueiredo Filho (2019) e Grolla e Nishijima (2019), ambas publicadas pela Revista Brasileira de Informação Bibliográfica em Ciências Sociais (BIB). No primeiro caso, Sampaio e Figueiredo Filho (2019) analisam os estudos que trataram da influência do dinheiro em eleiçóes municipais. Por sua vez, Grolla e Nishijima (2019) investigam os artigos publicados em língua inglesa que tinham como problema de pesquisa a influência da mídia em eleições. Esses dois textos são ilustrativos do esquema de trabalho da RS e, em ambos os casos, temos a utilização de softwares específicos para o tratamento dos dados coletados, o Harzing's Publish or Perish, no caso de Sampaio e Figueiredo Filho (2019), e o State of the Art through Systematic Review (StArt), desenvolvido pelo Laboratório de Pesquisa em Engenharia 
de Software (LaPES) da Universidade Federal de São Carlos, no caso de Grolla e Nishijima (2019).

\section{Como se faz uma revisão sistemática?}

Estabelecidas as vantagens da RS e alguns exemplos de sua aplicação, apresentamos algumas das formas de utilização da técnica. A lista de manuais de como fazer uma revisão sistemática é relativamente ampla. Temos exemplos de textos que narram o passo a passo dessa técnica nas mais variadas áreas, até mais próximas às Ciências Sociais (DACOMBE, 2017; DENYER e TRANFIELD, 2009; COOPER, 2010).

As etapas que cada protocolo de pesquisa segue variam em um pequeno número, de acordo com as recomendações dos pesquisadores em questão. Grolla e Nishijima (2019), por exemplo, por meio das orientaçóes de Kitchenham (2004), estabelecem três fases para a aplicação do método; Sampaio e Figueiredo Filho (2019), com base em Cooper (2010), estabelecem sete etapas. Limitando-nos a esses dois exemplos, o Quadro 1 lista quais são as etapas seguidas por essas orientações.

Quadro 1 - Etapas da Revisão Sistemática

\begin{tabular}{l|l|l}
\hline & Kitchenam (2004) & Cooper (2010) \\
\hline $\mathbf{1}^{\circ}$ etapa & Protocolo do planejamento & Pergunta de pesquisa \\
\hline $2^{\circ}$ etapa & Execução & Coleta da literatura \\
\hline $3^{\circ}$ etapa & Análise dos resultados & Coleta de informaçóes sobre cada estudo \\
\hline $4^{\circ}$ etapa & - & Avaliação da qualidade do material selecionado \\
\hline $5^{\circ}$ etapa & - & Análise e síntese dos estudos \\
\hline $6^{\circ}$ etapa & - & Interpretação dos resultados \\
\hline $7^{\circ}$ etapa & - & Apresentação das conclusóes \\
\hline
\end{tabular}

Fonte: Elaborado pelos autores.

Note-se que Cooper (2010) estabelece mais claramente quais são as várias etapas da aplicação do método. Embora o autor detalhe com maior precisão as fases da condução da técnica, as duas estratégias apresentadas no Quadro 1 não destoam muito. Em ambos os casos, temos a necessidade de estabelecer uma pergunta de pesquisa que será investigada em uma base de dados, que resultará em uma lista de artigos, teses ou dissertaçôes para serem analisadas a partir de variáveis específicas. Disso decorre a apresentação da RS, que poderá, ou não, ser processada em softwares desenvolvidos para esse fim em específico. 
Apesar da existência de várias outras orientações de como conduzir uma RS (DACOMBE, 2017; PETTICREW e ROBERTS, 2006), nos valemos da estratégia proposta por Kitchenam (2004). Acreditamos que o protocolo proposto permitiu a construção de um banco de dados representativo e que pode ser replicado ${ }^{2}$. Na seção seguinte, indicamos os passos de nossa investigação.

\section{O modelo de análise}

A revisão sistemática empreendida aqui foi constituída de três fases: planejamento, execução e análise dos resultados (GROLLA e NISHIJIMA, 2019; KITCHENHAM, 2004). Na primeira fase é estabelecida a questão ou fenômeno que é do interesse dos pesquisadores revisar, as variáveis que serão coletadas, bem como os critérios de inclusão/exclusão das pesquisas na análise final; na segunda fase a busca é realizada nos bancos de dados de periódicos de acordo com os critérios definidos anteriormente; e, por fim, os resultados são analisados.

Centramo-nos na questão: qual o impacto do uso do aplicativo WhatsApp nas eleiçôes? A partir desse ponto inicial, como exposto na Figura 1, a literatura de interesse do trabalho aqui empreendido é aquela em que são mencionados e estudados os dois fenômenos: eleiçóes e WhatsApp. Em termos formais, trabalhamos com artigos publicados em periódicos e em anais de eventos científicos, tal como realizado por Sampaio e Figueiredo Filho (2019). Os termos de pesquisa foram: "WhatsApp" e "Elections". O recorte temporal cobriu o período de 2010 até 2019, seleção definida a partir do ano de criação do aplicativo de mensagens WhatsApp até a atualidade.

\footnotetext{
${ }^{2}$ Os artigos estão destacados nas referências bibliográficas.
} 
64 | Bruno Schaefer, Tiago Barbosa, Sara Epitácio e Roberta Resende

Figura 1 - Literatura de interesse

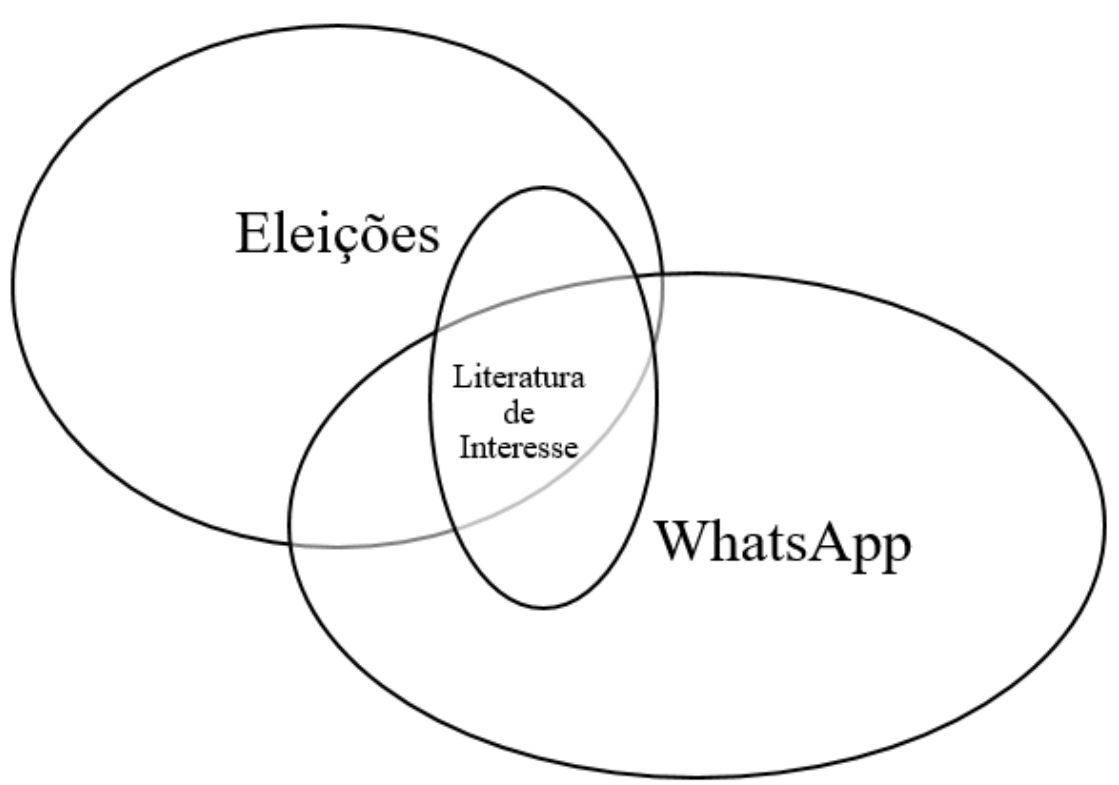

Fonte: Elaborado pelos autores.

Diante dessa literatura selecionada, escolhemos dois filtros de exclusão para montarmos o banco de dados final. Em primeiro lugar, além de observarmos se a publicação constava em anais de evento científico ou periódico, também atentamos para o uso de artigos escritos e/ou publicados por cientistas sociais ${ }^{3}$. Esse filtro se deve ao fato de que, no intuito de dialogar com a produção internacional da área, estudos como o da área de computação foram restringidos, ao menos aqueles publicados somente por pesquisadores dessa área. Em segundo lugar, foi considerado se constavam no resumo, título e/ou palavras-chave os termos "WhatsApp" e "Elections", ou suas diferentes grafias em línguas distintas. Como exposto na Figura 2, montamos, ao fim do processo, um banco de dados com 26 artigos que foram analisados de maneira sistemática.

3 Partimos de uma visão ampla de Ciências Sociais, que inclui áreas como Comunicação Social, Direito e Estudos sobre Religiáo, desse modo podemos ampliar o escopo de inferências e resultados produzidos. 
Figura 2 - Etapas da revisão sistemática da pesquisa

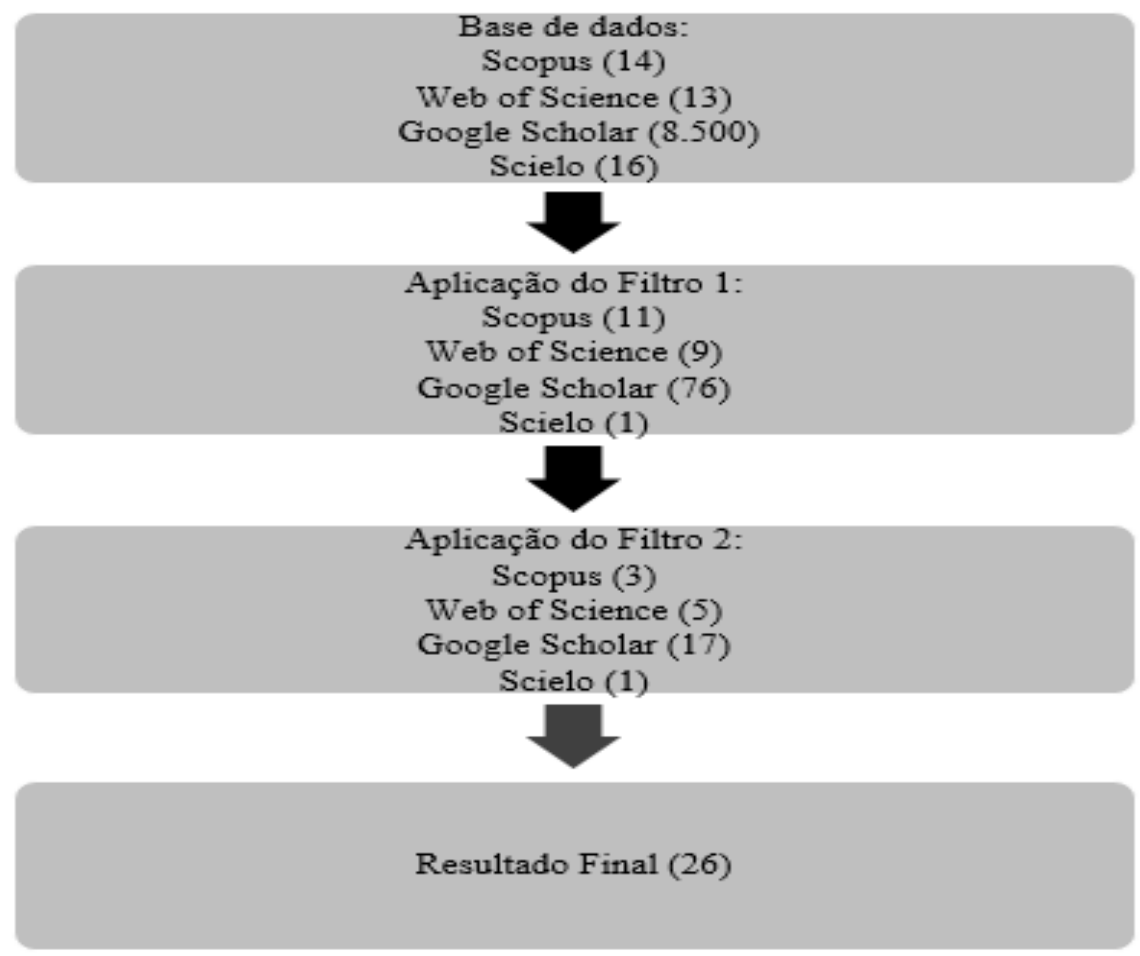

Fonte: Elaborado pelos autores.

Após a definição da nossa literatura de interesse e dos termos utilizados na busca para a condução da revisão sistemática, definimos quais seriam as variáveis analisadas. Separamos as variáveis como fizeram Sampaio e Figueiredo Filho (2019). Elas foram agrupadas em três grupos: formal, metodológica e substantiva. Com essa divisão, os dados variam desde informações sobre a quantidade de autores e universidade dos pesquisadores que publicaram os textos (dimensão formal), até se os textos tinham hipótese, fontes de pesquisa (metodológica) e seus resultados (substantiva). O Quadro 2 resume os três tipos de variáveis e as informações que foram coletadas: 
Quadro 2-Variáveis coletadas para revisão sistemática

\begin{tabular}{|c|c|c|c|}
\hline Dimensão & Variável & Descrição & Mensuração \\
\hline \multirow[t]{7}{*}{ Formal } & Título & Indica o título da publicação & Nominal \\
\hline & No de Autores & Quantidade de autores & Discreta \\
\hline & Universidade Autor 1 & $\begin{array}{l}\text { Indica a qual Universidade o primeiro } \\
\text { autor está vinculado }\end{array}$ & Nominal \\
\hline & $\begin{array}{l}\text { País da Universidade } \\
\text { Autor } 1\end{array}$ & $\begin{array}{l}\text { Indica a qual país o primeiro autor está } \\
\text { vinculado }\end{array}$ & Nominal \\
\hline & Formação & $\begin{array}{l}\text { Indica a formaçáo do primeiro autor } \\
\text { em seu maior nível de escolaridade }\end{array}$ & Nominal \\
\hline & Tipo de Publicaçáo & $\begin{array}{l}\text { Trabalho publicado em evento } \\
\text { científico ou periódico }\end{array}$ & $\begin{array}{l}\text { Dummy }(0=\text { Evento; } \\
1=\text { Periódico })\end{array}$ \\
\hline & Ano & Ano da publicação & Nominal \\
\hline \multirow[t]{17}{*}{ Metodológica } & Resumo & Publicação possui resumo & Dummy (1=Sim; 0=Náo) \\
\hline & Problema de Pesquisa & $\begin{array}{l}\text { Problema de pesquisa identificável após } \\
\text { leitura do paper }\end{array}$ & Dummy (1=Sim; 0=Náo) \\
\hline & Problema de Pesquisa & Qual a pergunta de pesquisa & Nominal \\
\hline & Tipo de Inferência & $\begin{array}{l}\text { Indica se a inferência da pergunta de } \\
\text { pesquisa é explicativa ou interpretativa }\end{array}$ & $\begin{array}{l}\text { Dummy (1=Explicativa; } \\
0=\text { Interpretativa) }\end{array}$ \\
\hline & Hipótese Identificável & $\begin{array}{l}\text { Hipótese de pesquisa identificável após } \\
\text { leitura do paper }\end{array}$ & Dummy (1=Sim; 0=Não) \\
\hline & Metodologia & $\begin{array}{l}\text { Informaçáo sobre os métodos utilizados } \\
\text { no resumo ou na primeira seção do } \\
\text { trabalho }\end{array}$ & Dummy (1=Sim; 0=Náo) \\
\hline & Metodologia & Qual metodologia é empregada & Nominal \\
\hline & Fonte de Dados & $\begin{array}{l}\text { Indica como foram coletados os dados } \\
\text { do paper }\end{array}$ & $\begin{array}{l}\text { Categórica }(0=\text { Primária; } \\
1=\text { Secundária; } 2=\text { Primária e } \\
\text { Secundária) }\end{array}$ \\
\hline & Técnicas de Análise & Descreve o tipo de método utilizado & Nominal \\
\hline & $\begin{array}{l}\text { Número de Técnicas } \\
\text { Empregadas }\end{array}$ & $\begin{array}{l}\text { Descreve o número de métodos } \\
\text { utilizados }\end{array}$ & Discreta \\
\hline & Recorte Temporal & Ano das eleiçôes analisadas & Nominal \\
\hline & $\begin{array}{l}\text { Tempo Entre Eleiçáo e } \\
\text { Publicaçáo }\end{array}$ & $\begin{array}{l}\text { Indica o tempo entre a publicação e o } \\
\text { ano analisado }\end{array}$ & Discreta (em anos) \\
\hline & Unidade de Análise & Especifica a unidade de análise & Nominal \\
\hline & País Pesquisado & Indica qual o país pesquisado & Nominal \\
\hline & Mesmo País & $\begin{array}{l}\text { Indica se o país analisado é o mesmo } \\
\text { do autor(a) }\end{array}$ & Nominal \\
\hline & Número de Casos & Indica o número de casos analisados & Discreta \\
\hline & Tipo de Eleiçáo & Indica o tipo de eleiçáa analisada & Nominal \\
\hline Substantiva & Resultados & Quais foram os resultados encontrados & Nominal \\
\hline
\end{tabular}

Fonte: Elaborado pelos autores a partir de Sampaio e Figueiredo Filho (2019).

Este foi o protocolo de coleta dos dados. Na próxima seçáo tratamos da análise dos resultados. 


\section{Análise dos Resultados}

Para uma melhor exposição dos resultados de nossa RS, dividimos a análise dos resultados em três subseções que cobrem as dimensões formal, metodológica e substantiva dos artigos. No caso da última, ainda há uma nova divisão, com o intuito de demonstrar os distintos resultados encontrados pelos trabalhados analisados.

\section{Dimensão Formal}

Em primeiro lugar, como exposto na Figura 3, construímos uma nuvem de palavras a partir dos títulos dos artigos. As palavras que mais aparecem nos títulos dos trabalhados são, respectivamente: WhatsApp, Election(s) e Political. Todas as palavras foram traduzidas para o inglês para possibilitar comparação.

Figura 3 - Nuvem de palavras a partir dos títulos dos artigos.

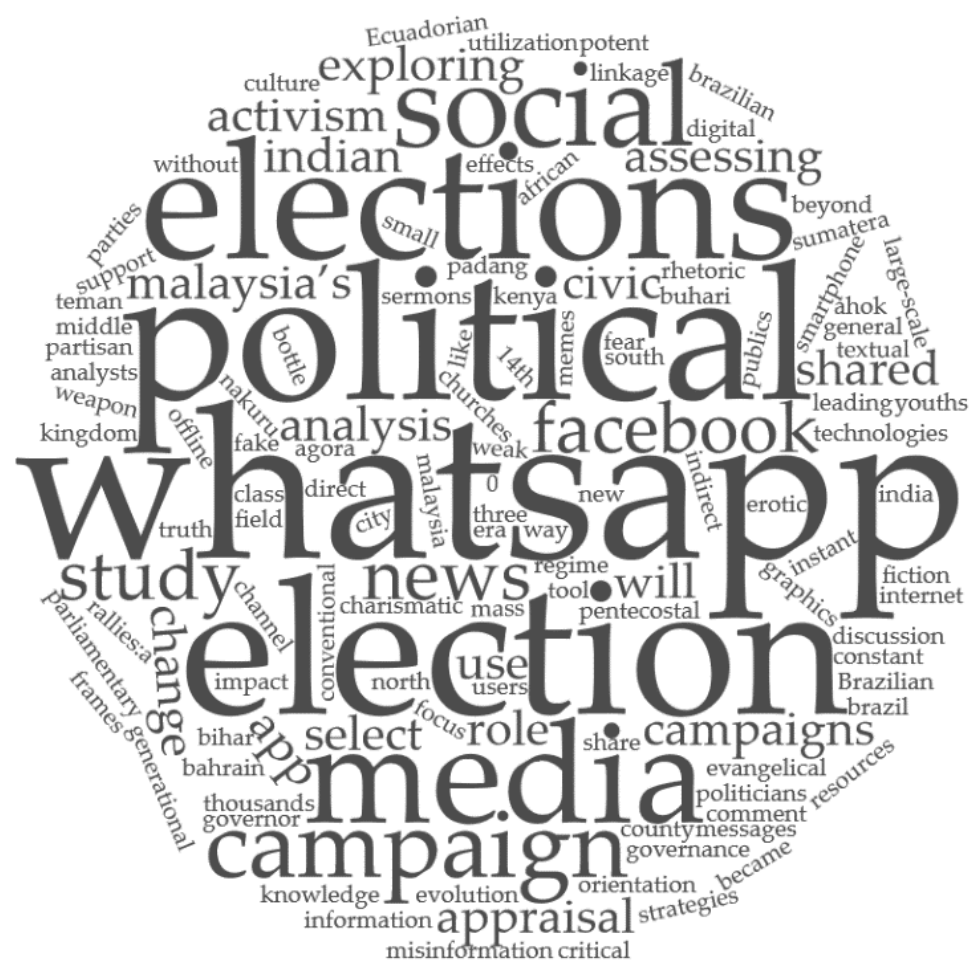

Fonte: Elaborado pelos autores.

Dos 26 artigos analisados, oito (30,8\%) foram publicados em eventos científicos, e os demais em diversos periódicos distintos - usualmente na área de 
Ciências Sociais (88,5\%). A média de autores nos artigos foi de 2,38 (mediana de dois), o que indica planejamentos coletivos de pesquisa, e está de acordo com as médias encontradas nos trabalhos da área. Conforme apontado por Henriksen (2016), em um inventário de produções de Ciências Sociais no período de 1980 a 2013 indexadas no Web of Science, a tendência em todas as disciplinas do campo, desde a Psicologia até a Ciência Política, é o aumento médio do número de autores em publicaçóes científicas.

Em relação à área de formação de autores e autoras dos trabalhos, Ciência Política e Comunicação Social são as disciplinas que lideram o número de produções ( $50 \%$ da amostra). Como grande parte dos trabalhos foram produzidos em coautoria, outras áreas também aparecem, como Ciências da Computação, Direito, História, Antropologia e Sociologia. A grande diversidade de disciplinas que produziram sobre a temática se reflete na heterogeneidade da construção de problemas, aportes teóricos e técnicas de coleta e análise de dados dos artigos analisados.

Apesar de o WhatsApp ter sido fundado em 2009 e iniciarmos nossa coleta de dados em 2010, o primeiro trabalho que consta em nossa amostra foi publicado em 2015. No ano seguinte, foram publicados dois artigos, depois seis, sete e dez, respectivamente. Ou seja, o último ano de nossa coleta foi o de maior produtividade sobre a temática de WhatsApp em eleiçôes, especialmente com artigos tendo por objeto de pesquisa as eleiçóes presidenciais brasileiras de 2018. Por mais que os estudos sobre o impacto da mídia em resultados eleitorais sejam antigos nas Ciências Sociais, em geral, e na Ciência Política em particular (GROLLA e NISHIJIMA, 2019), a produção sobre o WhatsApp ainda é muito recente. Na próxima subseção destacamos a dimensão metodológica dos artigos produzidos.

\section{Dimensão Metodológica}

O objetivo nesta subseção é observar como são construídos metodologicamente os trabalhos. É preciso ressaltar, primeiramente, a grande heterogeneidade nas pesquisas, tanto em termos da construção dos problemas a serem respondidos, na formulação dos desenhos de pesquisa, coleta e análise dos dados, bem como em relação aos casos escolhidos como objetos de análise.

Os países mais analisados nos trabalhos foram: Brasil, Índia, Nigéria e Indonésia, respectivamente. Esse dado se explica pelo nível de eleitores com acesso - e uso diário - do WhatsApp nesses contextos. Em termos proporcionais, cerca de 56\% da população brasileira tem acesso ao WhatsApp, e esse número é de $28 \%$ na Índia, $41 \%$ na Nigéria e $40 \%$ na Indonésia (CLEMENT, 2019). Em termos absolutos, o 
maior mercado para o aplicativo se encontra na Índia, com mais de 400 milhóes de usuários (SINGH, 2019). É interessante notar quais eleiçóes são analisadas: no caso brasileiro, o pleito presidencial de 2018, em que o WhatsApp foi utilizado de forma extensiva como estratégia de campanha, foi o foco de análise de todos os trabalhos sobre o país. No caso da Indonésia e da Índia, mais de um pleito foi analisado, enquanto os trabalhos sobre a Nigéria centraram-se nas eleiçóes de 2015.

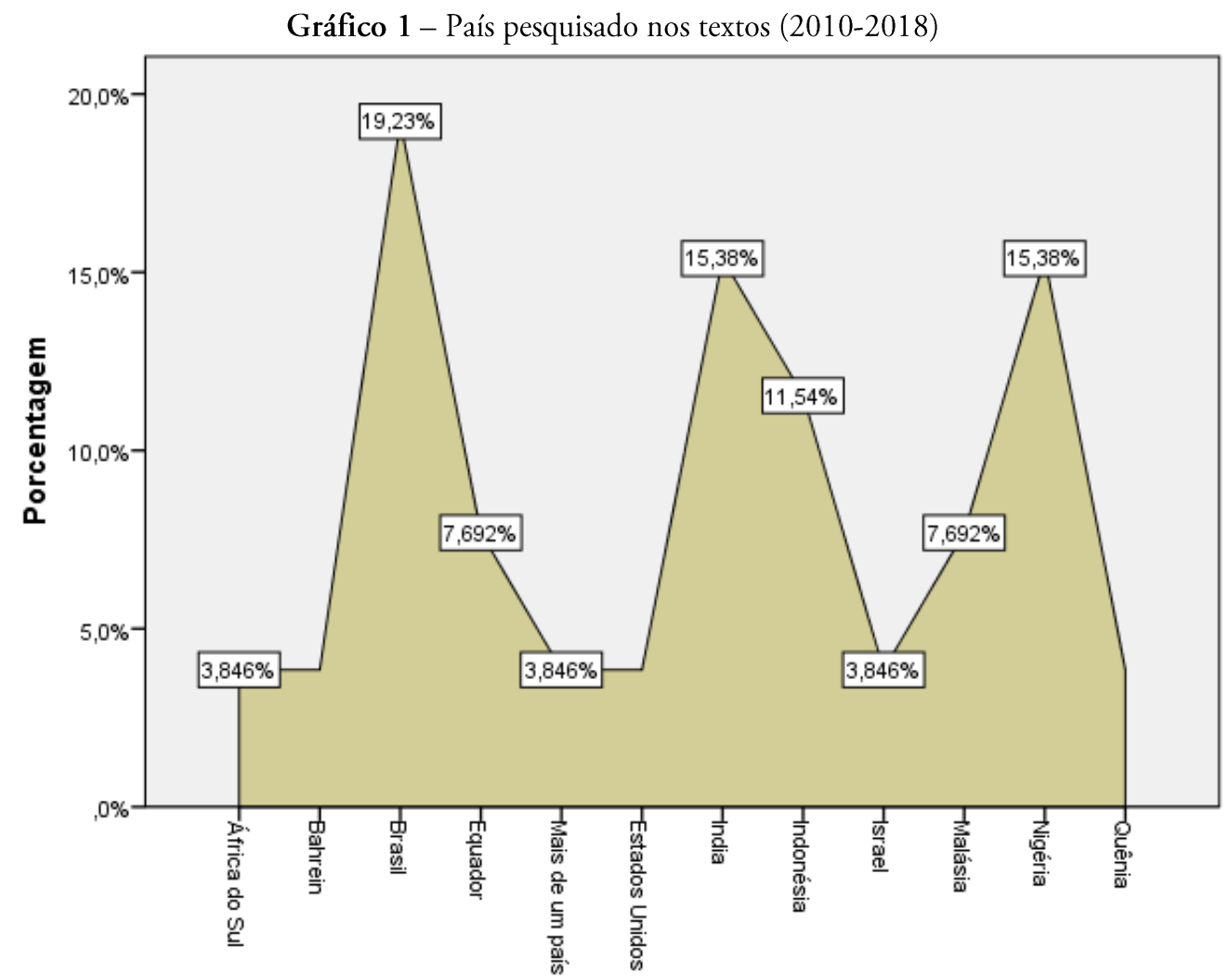

Fonte: Elaborado pelos autores.

Em termos de quem produz a pesquisa, contabilizamos a universidade a que o primeiro autor(a) estava vinculado(a) no momento da publicação do trabalho. Ao total, $73,1 \%$ da população (ou 19 pesquisadores) trabalharam com dados do próprio país. No caso brasileiro, dois dos cinco trabalhos produzidos foram realizados por pesquisadores vinculados a universidades estrangeiras (Estados Unidos e Inglaterra). Esse resultado demonstra que, apesar de as universidades europeias e norte- 
americanas serem líderes em impacto e relevância acadêmica (ORTEGA e AGUILLO, 2009), o estudo sobre o WhatsApp e sua relação com eleições não foi significativo, e essa característica talvez possa ser explicada em virtude da não popularidade, proporcionalmente, do aplicativo nas regióes.

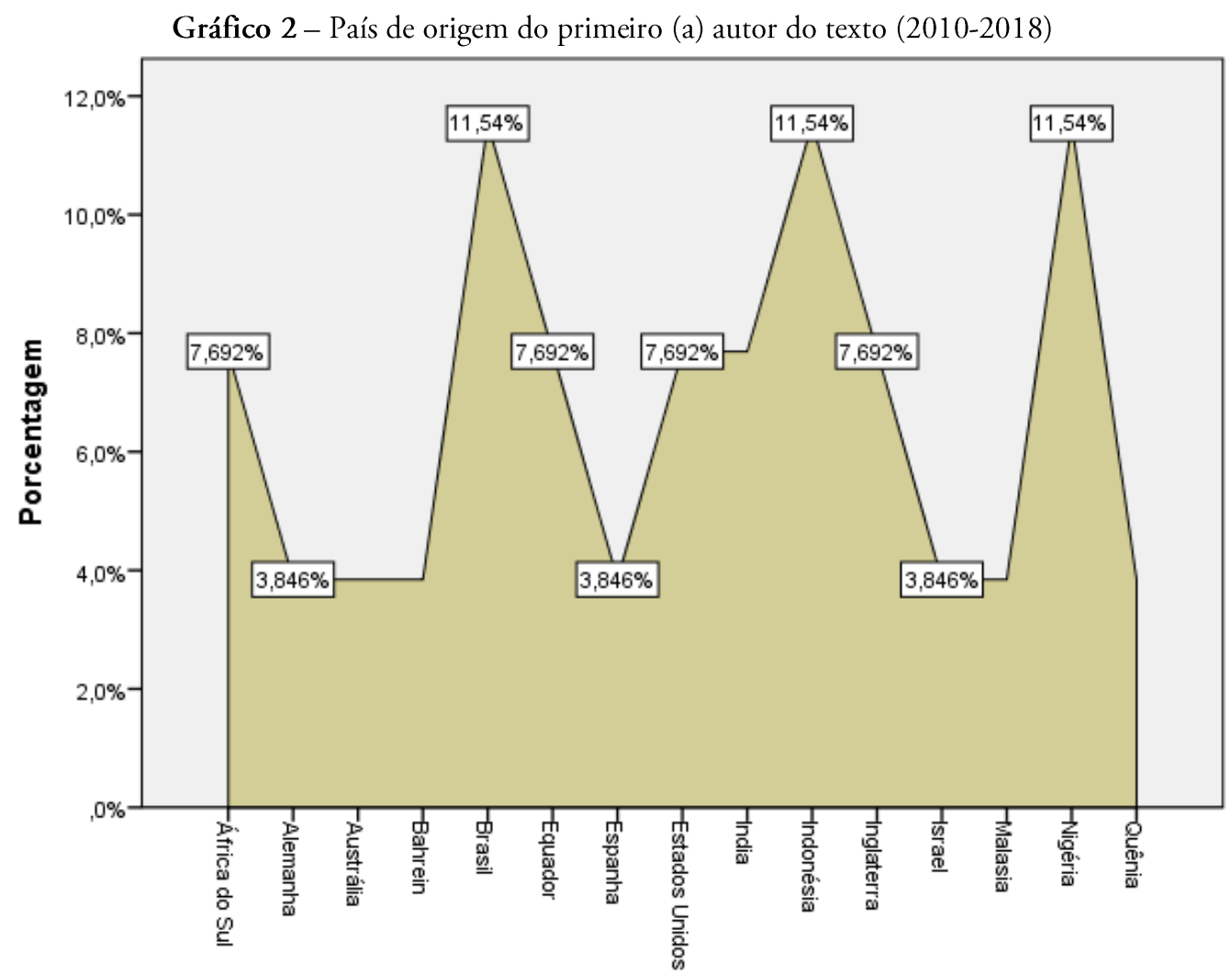

Fonte: Elaborado pelos autores.

Quanto ao tipo de eleição analisada, conforme exposto na Tabela 1, mais da metade dos trabalhos investigam pleitos presidenciais (Nigéria, Brasil e Equador), com atenção para eleições parlamentares (Índia) e para governos de províncias (Indonésia e Quênia). O único caso que não aplica é do trabalho de Gil de Zúñiga, Ardèvol-Abreu e Casero-Ripollés (2019), que conduz um survey com eleitores de três países em momentos não eleitorais, o único trabalho que parte de uma lógica comparativa na construção do objeto. 
Tabela 1 - Tipo de Eleição analisada nos textos (2010-2019):

\begin{tabular}{l|c}
\hline Tipo de Eleiçáo & $\mathbf{\%}$ \\
\hline Eleição Presidencial & 53,85 \\
\hline Eleição Parlamentar & 26,92 \\
\hline Governo do estado & 15,38 \\
\hline Não se aplica & 3,846 \\
\hline
\end{tabular}

Fonte: Elaborado pelos autores.

Existem grandes diferenças entre os trabalhos em todas essas questóes, o que necessariamente modifica como os resultados são apresentados e interpretados. Haverland e Yanow (2012) traçam uma diferenciação entre métodos e metodologia. Conforme os autores, a confusão entre os termos tende a ocorrer inúmeras vezes, o que afeta a construção de pesquisas e análise dos resultados. Enquanto método se refere às ferramentas e técnicas utilizadas em um trabalho, metodologia se refere a um nível mais amplo: as construçôes ontológicas e epistemológicas que balizam a adoção de um método ou outro. Precisamente nesse ponto é que se torna necessário diferenciar a construção de conhecimento proposta por metodologia quantitativa ou qualitativa. Enquanto para os pesquisadores orientados por um desenho quantitativo a principal questáo seria "explicar" determinado fenômeno, usualmente construindo inferências causais: o efeito de $\mathrm{X}^{1}$ e $\mathrm{X}^{2}$ sobre $\mathrm{Y}$, por exemplo (SÁTYRO e REIS, 2014); pesquisadores orientados por um desenho qualitativo de pesquisa tendem a se concentrar na "interpretação" de determinados resultados (HAVERLAND, 2010). A escolha de ferramentas para se chegar aos resultados finais tende a ser coerente com essa diferença de nível ontológico, mas fundamentalmente a diferenciação é detectada no próprio momento de formulação do problema de pesquisa (BOURDIEU, CHAMBODERON e PASSERON, 2015).

Dito isso, é possível separar os trabalhados analisados em termos das perguntas que buscam responder: de um lado trabalhos focados na interpretação dos sentidos do WhatsApp como ferramenta política e as estratégias dos atores que se engajam em seu uso (DAMANIK, 2018); e, do outro lado, aqueles centrados na explicação dos efeitos - estatísticos - do uso do WhatsApp sobre a decisão do voto (eleitores), a explicação dos efeitos do uso de WhatsApp para campanhas políticas (partidos e candidatos), bem como a dinâmica de compartilhamento de notícias em grupos do/no aplicativo (ESPINOSA, VALENZUELA e CADEÑO, 2017). Considerando essa divisão, 12 dos trabalhos partem de lógicas quantitativas na construção dos problemas e análise dos dados, enquanto 14 partem de lógicas 
qualitativas. No primeiro caso, usualmente os pesquisadores se utilizam de técnicas de análise estatística: descritiva ou inferencial, enquanto, no segundo caso, as técnicas de análise são análise de discurso, análise documental, entrevistas semiestruturadas com eleitores e/ou candidatos e observação participante.

São quatro as unidades de análise nos artigos: partidos ou candidatos $(38,5 \%)$, eleitores $(26,9 \%)$, grupos de WhatsApp $(26,9 \%)$ e outras organizações $(7,7 \%)^{4}$. Quando cruzamos essa informaçáo com o tipo de pergunta realizada, podemos observar - a partir dos resíduos padronizados ajustados - maior concentraçáo de estudos qualitativos focados em partidos ou candidatos, ou seja, nos sentidos das estratégias desses atores ao utilizar o WhatsApp, bem como maior concentração de estudos quantitativos focados em grupos de WhatsApp e nos eleitores. No primeiro caso, os pesquisadores e pesquisadoras tendem a utilizar a seguinte estratégia para conseguir dados: buscam no Google links de grupos públicos de WhatsApp, a partir de uma seleção dos grupos que de alguma forma estão vinculados a algum candidato ou partido, a equipe entra no grupo e passa a coletar informaçôes que são compartilhadas. Enquanto alguns autores "avisam" aos membros do grupo que estão realizando uma pesquisa e pedem consentimento dos membros (NARAYANAN et al., 2019; MACHADO et al., 2019), outros não realizam esse aviso e não pedem consentimento (CHAGAS, MODESTO e MAGALHÃES, 2019), se valendo do protocolo conhecido, nas Ciências da Saúde, como "pesquisa encoberta" (PADILHA et al., 2005). A ideia é de que se os participantes souberem de que há um pesquisador observando suas ações, os comportamentos se alterariam. No segundo caso, quando a pesquisa se foca em eleitores, a técnica empregada para a coleta de dados é, geralmente, survey.

Quando se comparam os números de casos analisados em cada tipo de trabalho, as diferenças são significativas: em média, estudos qualitativos trabalham com 11 casos, enquanto estudos quantitativos trabalham com 459 casos $^{5}$.

\footnotetext{
${ }^{4}$ Um trabalho enfoca como pastores de três igrejas pentecostais da África do Sul buscam influenciar seus "fiéis" a partir de mídias sociais, com especial destaque ao WhatsApp, e o outro enfoca a mídia tradicional.

${ }^{5}$ Foi realizado o Teste $\mathrm{T}$ de diferença de média para observar a significância dessa diferença. $\mathrm{O}$ valor de F foi 16,54 , e a significância 0,001 .
} 
Tabela 2 - Unidade de análise dos textos publicados (2010-2018)

\begin{tabular}{|c|c|c|c|c|}
\hline $\begin{array}{l}\text { Unidade de } \\
\text { Análise }\end{array}$ & Estatísticas & Quali & Quanti & Total \\
\hline \multirow{3}{*}{$\begin{array}{l}\text { Partidos ou } \\
\text { Candidatos }\end{array}$} & $\mathrm{N}$ & 9 & 1 & 10 \\
\hline & $\%$ & $90,0 \%$ & $10,0 \%$ & $100,0 \%$ \\
\hline & Resíduos padronizados ajustados & 2,9 & $-2,9$ & \\
\hline \multirow[t]{3}{*}{ Eleitores } & $\mathrm{N}$ & 1 & 6 & 7 \\
\hline & $\%$ & $14,3 \%$ & $85,7 \%$ & $100,0 \%$ \\
\hline & Resíduos padronizados ajustados & $-2,5$ & 2,5 & \\
\hline \multirow{3}{*}{$\begin{array}{l}\text { Grupos de } \\
\text { WhatsApp }\end{array}$} & $\mathrm{N}$ & 2 & 5 & 7 \\
\hline & $\%$ & $28,6 \%$ & $71,4 \%$ & $100,0 \%$ \\
\hline & Resíduos padronizados ajustados & $-1,6$ & 1,6 & \\
\hline \multirow{3}{*}{$\begin{array}{l}\text { Outras } \\
\text { Organizações }\end{array}$} & $\mathrm{N}$ & 2 & 0 & 2 \\
\hline & $\%$ & $100,0 \%$ & $0,0 \%$ & $100,0 \%$ \\
\hline & Resíduos padronizados ajustados & 1,4 & $-1,4$ & \\
\hline
\end{tabular}

Fonte: Elaborado pelos autores.

O único trabalho que enfoca os eleitores e não se vale de lógica quantitativa foi produzido por Oyebode e Adegoju (2017) e busca responder a seguinte questão: “Quais os recursos utilizados pela comunidade 'online' nigeriana para colocar no 'ar' suas visões, construir sentidos atitudinais e conseguir atenção pública sobre a representação de candidatos na eleição de 2015?”, se utilizando do método de análise de discurso. Os únicos trabalhos que enfocam grupos de WhatsApp e não se valem de lógica quantitativa foram de Omanga (2019) e Machado et al. (2019). No primeiro caso, o autor busca analisar os sentidos do uso do WhatsApp para a melhora da governança de uma província queniana e o impacto desses sentidos para a eleição de governador, enquanto Machado et al. (2019) trabalham com informaçóes de 130 grupos de WhatsApp utilizados nas eleiçôes de 2018 para criar uma tipologia de notícias falsas. Nesse sentido, o objetivo não é analisar o efeito das fake news sobre o voto, mas criar uma tipologia que posteriormente possa ser usada para esse propósito.

Quanto à coleta de dados, pode-se separar os trabalhos entre aqueles que coletaram criando sua base de informaçóes (primária), aqueles que se utilizaram de outros trabalhos ou estatísticas oficiais (secundária), e aqueles que mesclaram as duas formas de obtenção de informações. Como podemos observar na Tabela 3, a maior parte dos trabalhos de lógica quantitativa trabalharam com dados coletados pelos próprios autores, por meio de surveys e mineração de dados. 
74 | Bruno Schaefer, Tiago Barbosa, Sara Epitácio e Roberta Resende

Tabela 3 - Fonte de dados dos trabalhos publicados (2010-2018)

\begin{tabular}{|c|c|c|c|c|}
\hline Fonte de Dados & Estatísticas & Quali & Quanti & Total \\
\hline \multirow[t]{3}{*}{ Primária } & $\mathrm{N}$ & 3 & 11 & 14 \\
\hline & $\%$ & $21,4 \%$ & $78,6 \%$ & $100,0 \%$ \\
\hline & $\begin{array}{l}\text { Resíduos padronizados } \\
\text { ajustados }\end{array}$ & $-3,6$ & 3,6 & \\
\hline \multirow[t]{3}{*}{ Secundária } & $\mathrm{N}$ & 8 & 0 & 8 \\
\hline & $\%$ & $100,0 \%$ & $0,0 \%$ & $100,0 \%$ \\
\hline & $\begin{array}{l}\text { Resíduos padronizados } \\
\text { ajustados }\end{array}$ & 3,1 & $-3,1$ & \\
\hline \multirow{3}{*}{$\begin{array}{l}\text { Primária e } \\
\text { Secundária }\end{array}$} & $\mathrm{N}$ & 3 & 1 & 4 \\
\hline & $\%$ & $75,0 \%$ & $25,0 \%$ & $100,0 \%$ \\
\hline & $\begin{array}{l}\text { Resíduos padronizados } \\
\text { ajustados }\end{array}$ & ,9 &,- 9 & \\
\hline
\end{tabular}

Fonte: Elaborado pelos autores.

Quando comparadas as informações já elencadas nesta seção, podemos observar, no Gráfico 3, a vinculação entre objetos de estudo e fontes de dados. Utilizamos a análise de correspondência múltipla para mostrar graficamente os resultados, dado que, como afirmam Codato, Roeder e Suhurt (2018, p. 75): “A análise de Correspondência Múltipla (ACM) [...] permite uma visualização espacial dos dados e de sua distribuiçáo através de um mapa perceptual em um espaço multidimensional". Os dados das dimensôes indicam que o modelo está bem ajustado estatisticamente, e o resultado demonstra que a maior parte dos trabalhos que teve como unidade de análise grupos de WhatsApp se concentrou no caso brasileiro. Os trabalhos que se centraram na construção de bases de dados originais tendem a enfocar nos países com eleições presidenciais, enquanto os trabalhos sobre campanhas (partidos ou candidatos) centram-se nos casos de democracias parlamentaristas. 
Gráfico 3 - ACM - Objetos de estudo e fontes de dados

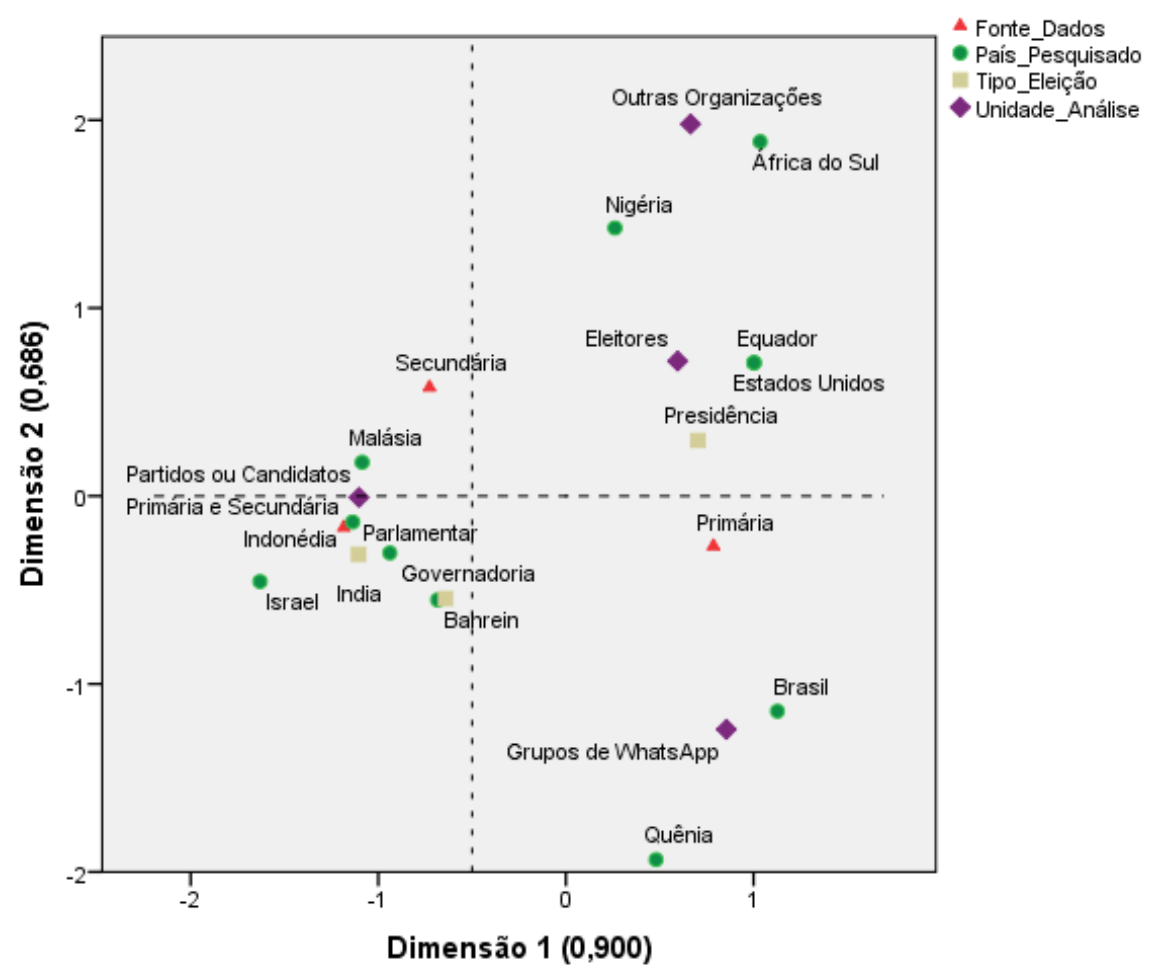

Fonte: Elaborado pelos autores.

$\mathrm{Na}$ próxima subseção tratamos da dimensão substantiva dos papers analisados, ou seja, quais são os resultados encontrados nos trabalhos em resposta à questão do impacto do WhatsApp em eleiçôes.

\section{Dimensão Substantiva}

Tratamos agora da dimensão substantiva dos trabalhos revisados. Focamos, especialmente, nos principais resultados encontrados. Essa foi a opção seguida dadas as diferenças entre os desenhos de pesquisa, conforme exposto anteriormente. Tratamos de expor os resultados das pesquisas de acordo com as unidades de análise desenvolvidas nos trabalhos.

\section{Como organizações e candidatos usam o WhatsApp?}

Sobre a utilização do WhatsApp por organizações/candidatos, é importante notar que os trabalhos enfatizam como as novas mídias foram utilizadas com o 
intuito de modificar o status quo e tornar o acesso à informação mais plural, em contraponto a regimes políticos já institucionalizados e detentores dos meios de comunicação convencionais. Nesse sentido, em que pese a existência de fake news, alguns dos trabalhos apontam para a importância do uso do WhatsApp, Facebook, entre outros, como forma de democratização, ativismo, pluralismo e incremento da competição política.

Para Tapsell (2018), o uso do smartphone e as mídias Facebook e WhatsApp foram mecanismos importantes de disseminação do discurso político. A partir de entrevistas e participação em comícios organizados pelos principais articuladores e estrategistas da campanha eleitoral ocorrida na Malásia em 2018, assim como da participação em alguns grupos vinculados à campanha eleitoral do governo e oposição, o autor conclui que o smartphone foi utilizado como um dispositivo subversivo de contestação política para contornar a mídia convencional controlada pelo governo. Ainda com enfoque nas eleições de 2018, Nizah e Bakar (2019) concentram-se em compreender como o conteúdo político do WhatsApp se sobrepôs ao disseminado no Facebook e, dessa forma, contribuiu para que o cidadão aderisse à mudança de governo, concretizada com a derrota do Borisan Nasional após 60 anos de hegemonia política. Essa mudança, apesar de ter encontrado o seu apogeu nas eleiçôes de 2018, é resultado de um processo iniciado nas eleiçóes gerais de 2008. Esses veículos de comunicação em massa são promissores em sociedades marcadas por um grande contingente eleitoral, porém seu uso requer alguns cuidados e responsabilidades dos partidos políticos e usuários com a postagem e compartilhamento de material político para que a estabilidade nacional não seja prejudicada.

Com um olhar mais dedicado à comunicação política, Seteolu (2017) analisa as eleições ocorridas na Nigéria a partir da incorporação das novas mídias à teoria da agenda setting. Entretanto, em um contexto de maior democratização do acesso à informação, parte da mídia tradicional nigeriana optou por abrir mão da neutralidade jornalística e passou a assumir uma postura partidária na cobertura política e na interpretação de notícias sobre política. $O$ autor conclui que a influência das novas mídias no jogo político será ampliada, em termos qualitativos, caso haja a manutenção e proliferação de ferramentas de comunicação capazes de contribuir para a globalização das informaçóes e o desejo do eleitorado em obter informações críveis.

Ainda sobre as eleições nigerianas de 2015, Inyang (2016) destaca a relevância do uso de material visual pelo movimento "Buhari-Change", compartilhado em várias mídias sociais e sites de blogs e micro mensagens de texto como Twitter, 
Facebook e WhatsApp, em contestação ao governo do Partido Democrático do Povo, ocupante do governo nigeriano há 16 anos. Para o autor, a combinação de um pensamento criativo, mídia social, design visual e comunicação instantânea, baseado no "Design for Obama", forneceu um novo modelo para o ativismo político virtual e uma base para a competição e negociação do poder político na África. No espaço de mídias virtuais, o feedback sobre a eficiência da campanha ocorre de forma instantânea, o que possibilita redirecionamentos e mudanças de estratégias para ampliar o apelo das campanhas eleitorais.

Frahm-Arp (2015) constata, a partir de uma pesquisa etnográfica que conduz em três igrejas pentecostais carismáticas ${ }^{6}$ da África do Sul, meses antes da eleição presidencial de 2014, que todas, de alguma forma, encorajam debates sobre política nos espaços das próprias igrejas e em seus espaços virtuais (sites, podcasts, páginas do Facebook e grupos de WhatsApp), mas o grau de comprometimento é variável. Enquanto a Igreja 'Grace Bible Church' foi menos ativa no pleito, a Igreja 'Acts of Faith Harvesters', a partir de seus pastores, apoiou o candidato presidencial Zuma (do partido Congresso Nacional Africano - ANC), inclusive enviando mensagens de WhatsApp para os fiéis. A influência surtiu efeito em vários fiéis entrevistados pela pesquisadora: "To them it did not seem problematic that they only engaged with ANC candidates; they believed that their pastor knew what was best for them when he did not invite people from any other parties" (FRAHM-ARP, 2015, p. 129).

Mahapatra e Plagemann (2019) focam nas eleiçóes parlamentares de 2019 na Índia, em especial nas estratégias digitais dos dois principais partidos políticos do país: BJP (Bharatiya Janata Party) e INC (Indian National Congress). O BJP, liderado pelo atual primeiro ministro, Narendra Modi, pôde criar milhares de grupos de WhatsApp localizados geograficamente durante as eleiçóes, de modo que o compartilhamento de mensagens tinha um conteúdo local: em áreas mais urbanizadas, focava-se nos aspectos "desenvolvimentistas" da plataforma do governo de Modi, enquanto em áreas rurais o foco foi o compartilhamento de mensagens de cunho religioso, especialmente de conteúdo Hindu e contra a comunidade muçulmana do país. Conforme apontam os autores, essa estratégia possibilitou o sucesso eleitoral, mas aumentou a polarização religiosa do país. No caso do INC, a campanha a partir do WhatsApp teve um caráter muito mais reativo do que ativo. $\mathrm{O}$

${ }^{6} \mathrm{O}$ que seria o equivalente, no caso brasileiro, às igrejas neopentecostais, como a Igreja Universal do Reino de Deus (IURD). 
partido e suas lideranças tiveram que se defender de acusaçóes de serem uma organização pró-muçulmana e reforçar uma imagem nacionalista. O sucesso de Modi e seu partido, conforme Mahapatra e Plagemann (2019), se deve também a uma estrutura muito mais profissionalizada no uso das redes sociais e, em especial, do WhatsApp: "Currently, their IT7 cell has 100-150 people on its payroll and around 1.2 million volunteers working for it" (MAHAPATRA e PLAGEMANN, 2019, p. $04)$.

Ou seja, as mídias sociais, e em especial o WhatsApp, são utilizados tanto por atores políticos de apoio aos governos quanto por atores em oposição. Mesmo em regimes políticos fechados, como o Bahrein, parlamentares utilizam o WhatsApp como forma de legitimação na arena política, comunicando-se com a população (ABDULLAH e ELGHOBASHY, 2017). De modo geral, os trabalhos que se centram nas campanhas ou em organizações não testam hipóteses específicas, mas constatam, a partir de técnicas como análise documental e de discurso, que o WhatsApp é percebido pelos atores políticos como uma ferramenta eficaz de disseminação de mensagens políticas (PRANAWA e HUMSONA, 2017; FAROOQ, 2018; HALEVA-AMIR, 2016; HASAN e JOHRI, 2017; SUMARTIAS, 2017).

\section{Qual a dinâmica de trocas de informação em grupos do WhatsApp?}

Como colocamos anteriormente, os pesquisadores que trabalham com dados oriundos dos grupos de WhatsApp se concentram nos grupos do aplicativo que possuem links de acesso abertos na internet. Resende et al. (2019), por exemplo, estão preocupados com a forma e dinâmica do compartilhamento de mensagens com notícias falsas (fake news) em uma amostra de 364 grupos de WhatsApp de apoio a partidos e candidatos brasileiros que competiram no pleito presidencial de 2018. A partir da análise de uma amostra de notícias compartilhadas nesses grupos, os autores codificaram as notícias em falsas e não-falsas, tendo como base seis sites de factchecking brasileiros ${ }^{8}$. Os principais achados dos autores foram que as fake news tendem a ter menos palavras do que mensagens "não-falsas", são mais negativas em

\footnotetext{
7 Tecnologia da informação.

8 "To identify misinformation in our textual messages, we collected facts there were previously checked as by fact-checking web fake sites and compared them the messages in (filtered) dataset. Specifically, we crawled checked information (news or claims) from six popular Brazilian fact-checking sites: "Aos fatos", "Me engana que eu posto", "e-farsas", "é ou não é (G1)", "Lupa" and "Boatos.org"” (RESENDE et al., 2019, p. 03).
} 
relação ao oponente do que positivas sobre o candidato apoiado, utilizam expressóes como "por favor", "compartilhe", "escute", ou seja, têm um efeito de urgência e se espalham entre grupos ideologicamente semelhantes, demorando mais que mensagens "não-falsas" para cruzar barreiras partidárias, o que denota que ficam mais tempo no sistema, ou seja, não são logo desacreditadas.

Mont'Alverne e Mitozo (2019) descobrem que a maior parte dos links compartilhados em grupos de WhatsApp públicos e orientados partidariamente (a amostra das autoras é de 213 grupos) têm como destino o site Youtube. Conforme as autoras: "A concentraçáo de conteúdo proveniente do YouTube [...] demonstra que as fontes tradicionais de notícias não receberam tanta atenção quanto as ferramentas digitais. A tendência parece ser de compartilhamento de conteúdo partidarizado [...]" (MONT'ALVERNE e MITOZO, 2019, p. 20). O site de notícias com maior compartilhamento em todos os grupos foi “O Antagonista”, favorável à candidatura de Jair Bolsonaro (PSL). É interessante notar que a campanha do segundo colocado, Fernando Haddad (PT), teve menos "movimentação" nos grupos do que candidatos como Ciro Gomes (PDT), Guilherme Boulos (PSOL) e Marina Silva (REDE).

Em uma comparação entre grupos públicos de esquerda (Fernando Haddad) e direita (Jair Bolsonaro), Bursztyn e Birnbaum (2019) demonstram diferentes dinâmicas de relacionamento no interior dos grupos. Os grupos de apoio a Jair Bolsonaro são mais conectados (mesmos usuários participam de vários grupos), mais ativos (compartilham mais notícias e links para vídeos do Youtube) e são mais distribuídos geograficamente. Os principais sites de notícias compartilhados nesses grupos são, conforme outros trabalhos encontraram, "O Antagonista" e o "Jornal da Cidade” (MACHADO et al., 2019). Chagas, Modesto e Magalhães (2019) propõem uma análise mais detida sobre o compartilhamento da mensagem "O Brasil virar Venezuela” em 158 grupos de apoio ao candidato Jair Bolsonaro. Os autores avançam em termos teóricos ao considerar os grupos de WhatsApp como espaço de sociabilidade política em que, ao contrário de outras redes sociais, o tipo de conversa é privada. A partir 11.118 mensagens trocadas nos grupos analisados, os autores criaram 20 códigos para classificar as mensagens que mencionavam a Venezuela. $\mathrm{O}$ uso da comparação entre o país vizinho e o Brasil se dava, entre os usuários, no sentido da vinculação entre o desastre econômico e humanitário da Venezuela e o que os governos de esquerda "poderiam" fazer. Conforme os autores, são o: “[...] envio de informaçôes aos demais membros e o caráter de difusão em escala estratégica de mensagens que configuram ou ao menos favorecem determinados enquadramentos" 
(CHAGAS, MODESTO e MAGALHÃES, 2019, p. 10). O volume de mensagens sobre a Venezuela ao longo do pleito se intensificou na semana anterior ao primeiro turno da eleição e foi fortemente dinamizado pelo uso profissional da rede: apenas um usuário foi responsável pelo compartilhamento de 341 mensagens ao longo do período analisado, e os dez usuários mais ativos foram responsáveis pelo compartilhamento de $8,1 \%$ das mensagens.

Como exposto no Gráfico 3, os estudos sobre grupos de WhatsApp se centraram no caso brasileiro. Os dois outros trabalhos com essa unidade de análise encontraram, para o caso indiano, que grande parte das imagens compartilhadas em grupos de WhatsApp de apoio dos partidos BJP (Bharatiya Janata Party) e INC (Indian National Congress) são "segregacionistas" e "conspiratórias", 34,5\% e 28,5\%, respectivamente, de um total de 200 imagens analisadas (NARAYANAN et al., 2019). No caso queniano, Omanga (2019) analisa o grupo de WhatsApp "Nakuru Analysts" (NA). A partir da teoria democrática deliberativa, o autor encontra evidências de que o espaço de discussão do grupo constituiu uma arena ativa entre os residentes da província de Nakuru no que concerne a maior participação política e a criação de novos atores políticos. Nesse sentido, em um país "parcialmente livre", conforme dados da Freedom House (c2019), o WhatsApp é visto como uma plataforma de democratização do acesso a informações sobre política e renovação do sistema político.

\section{Qual o efeito do WhatsApp nos eleitores?}

Os trabalhos que focam em eleitores como unidade de análise se dividem entre aqueles que buscam testar o efeito do WhatsApp sobre o conhecimento político (informações objetivas e subjetivas) e a participação política off-line. Ou seja, testar se as pessoas, ao se informarem, discutirem e se expressarem no WhatsApp, vão participar de outros eventos políticos fora da internet, como passeatas, campanhas políticas, abaixo-assinados e greves. Desta forma, esses trabalhos enfocam em mais casos e realizam testes estatísticos multivariados para testar os efeitos de cada variável. O outro grupo é composto por trabalhos mais descritivos que pontuam, por exemplo, quantas pessoas usam o WhatsApp para se informar e/ou conversar sobre política. A diferença, nesse sentido, é da construção do desenho da pesquisa para o teste de hipóteses.

Espinosa, Valenzuela e Cadeño (2017), Yamamoto, Kushin e Dalisay (2018) e Gil de Zúñiga,Ardèvol-Abreu e Casero-Ripollés (2019) são exemplos do primeiro grupo. Os autores conduzem surveys com 1136 (Equador), 630 (Estados Unidos) e 
1426 respondentes (Estados Unidos, Espanha e Nova Zelândia), respectivamente. São várias as hipóteses testadas. Espinosa, Valenzuela e Cadeño (2019) classificam o uso de redes sociais em geral (Facebook, Twitter e WhatsApp), e do WhatsApp, em particular, entre passivo e ativo. No primeiro caso, o uso de ferramentas digitais teria o objetivo de se obter informaçáo (informacional). No segundo caso, os usos seriam expressivos (formação de conteúdo), conversacional e de interação para com grupos ou agentes políticos (partidos e candidatos). Os autores consideram que o uso de ferramentas digitais, em especial o WhatsApp, teria um efeito positivo sobre a participação política off-line e acrescentam que cada tipo de uso teria um efeito diferenciado. A partir de testes de regressão linear multivariada (mínimos quadrados ordinais), os autores confirmam a primeira hipótese: o uso de redes sociais é um fator preditivo de maior participação política: "el uso político de redes sociales $(\beta=0,286)$ constituye el predictor que mayor impacto ejerce sobre el nivel de activismo político off-line” (ESPINOSA,VALENZUELA e CADEÑO, 2017, p. 137). É interessante notar que esse valor supera, inclusive, o efeito do pertencimento a grupos políticos, como partidos, sindicatos e outros movimentos. Quando decompostos os tipos de usos das redes sociais, os autores encontram efeito estatisticamente significativo apenas para os usos expressivos e de interação para com grupos ou agentes políticos. Os usos expressivos, geralmente pelo Twitter, e de contato com atores políticos (pelo WhatsApp), são fatores significativos de maior engajamento off-line, o que, conforme os autores, pode indicar novas modalidades de recrutamento político utilizadas por partidos e/ou candidatos.

Gil de Zúńiga et al. (2019) constroem um desenho de pesquisa bastante próximo ao de Espinosa, Valenzuela e Cadeño (2017), no entanto, focam somente no efeito do uso do WhatsApp, e não de outras redes sociais, sobre a participação política off-line, e decompóem as variáveis de acordo com faixas etárias. As principais hipóteses são de que o uso do WhatsApp para discussão política possui um efeito positivo sobre a participação política em outras esferas da vida pública e que esse efeito é maior entre os mais jovens. Os autores confirmam essas duas principais hipóteses, concluindo que: "WhatsApp may therefore constitute a major, privileged platform for activism-related information, which would explain its stronger influence on these forms of participation" (GIL DE ZÚNIGA, ARDĖVOL-ABREU e CASERO-RIPOLLÉS, 2019, p. 13). Em termos normativos consideram que o WhatsApp constitui uma plataforma de possível fortalecimento da democracia. 
Yamamoto, Kushin e Dalisay (2018) trabalham com outras variáveis dependentes. Apesar de os autores também testarem o efeito do WhatsApp sobre a participaçáo política off-line, o trabalho se centra na questão de explicar o efeito do uso do WhatsApp para consumo de notícias, entre outros aplicativos de mensagens, e o conhecimento político de eleitores. Nesse sentido, as variáveis dependentes são divididas em três conjuntos: conhecimento factual, conhecimento subjetivo e diferença entre ambos. O conhecimento factual foi medido a partir de uma série de perguntas sobre os candidatos à presidência dos Estados Unidos e seus respectivos planos de governo. O conhecimento subjetivo foi medido a partir de questóes sobre o quanto o eleitor se achava informado sobre o pleito, como, por exemplo: "em uma escala de 0 (discordo totalmente) e 5 (concordo totalmente), o quanto o(a) senhor(a) se considera um expert nas eleiçóes?” Depois de estandardizadas as respostas, os autores calcularam a diferença entre ambos os tipos de conhecimento. A partir de uma análise de regressão linear multivariada (mínimos quadrados ordinais), os autores encontram como resultado de que quanto mais o eleitor se informa sobre política a partir de aplicativos de mensagens, menor o conhecimento factual sobre candidatos e maior a diferença entre conhecimento factual e subjetivo, controlados os resultados por outras variáveis como raça, gênero, idade e nível de renda. Uma possível explicação seria a própria constituição do fluxo de informação no interior dos aplicativos, mais fechadas e próximas ideologicamente do usuário. Conforme os autores: "Filter bubbles formed by the user selectivity may limit factual learning while fostering the overestimation of how much one knows about politics" (YAMAMOTO, KUSHIN e DALISAY, 2018, p. 2383).

Os outros trabalhos que tiveram eleitores como unidade de análise partiram de análises descritivas dos resultados. Sánchez et al. (2018) realizam um survey com 389 eleitores equatorianos que participaram do pleito de 2017. Os autores encontram evidências de que o WhatsApp seria mais utilizado como ferramenta de informação política entre os respondentes mais velhos, enquanto o Facebook seria utilizado pelos mais jovens. Os resultados, no entanto, devem ser vistos com bastante parcimônia, dado que os autores fizeram afirmações a partir de um questionário online dentro de uma comunidade universitária, o que pode constituir uma amostra não representativa da população (SÁNCHEZ et al., 2018, p. 367).

Morah e Uzochuku (2018) encontram resultados semelhantes em survey realizado com 300 eleitores nigerianos de 18 a 40 anos. Quanto à obtenção de informação sobre política, $63,6 \%$ dos entrevistados responderam que utilizam o Facebook, e $18,1 \%$ o WhatsApp. No entanto, os pesquisadores vão além e 
perguntam se os eleitores haviam recebido alguma mensagem de candidatos ao pleito de 2015 no país: $49,2 \%$ responderam que sim e, destes, 37,9\% responderam que as mensagens recebidas tiveram impacto na posterior decisão do voto.

\section{Considerações finais}

Neste artigo, buscou-se utilizar a revisão sistemática como técnica para analisar as publicaçóes sobre a influência do WhatsApp em eleiçóes. Para isso, optouse pela utilização de três dimensóes de análise: formal, metodológica e substantiva. A dimensão formal revelou que a produção de trabalhos em autoria conjunta é predominante. A nuvem de palavras apresentada na Figura 3 apresenta um expressivo número de temas transversais presentes nos artigos, mesmo que estes compartilhem de uma mesma unidade de análise. Apesar de tratar-se de uma agenda de pesquisa recente, é perceptível o aumento crescente de publicações a partir do ano de 2015.

Sobre a dimensão metodológica, é importante destacar que tanto os países dos autores quanto os países analisados encontram-se predominantemente fora da Europa e Estados Unidos, concentrando-se, sobretudo, nas eleiçôes presidenciais de regiões de democratização recente, tais como África, Ásia e América Latina, as democracias da "terceira onda". Nesse trabalho, em virtude das categorias de análise utilizadas, não foi possível fazer inferências sobre a relação entre acesso à internet, uso de smartphone e WhatsApp e o processo eleitoral dos países. Entretanto, tal relação pode ser um elemento interessante para análises futuras. Sobre os trabalhos de metodologia quantitativa, foi frequente o uso de banco de dados produzidos pelos próprios autores a partir de surveys e de técnicas de mineração de dados a partir de grupos de WhatsApp.

Ao explorar os trabalhos a partir do uso da dimensão substantiva, foi possível perceber que, apesar da semelhança em relação à origem democrática dos países, há uma variação no nível de criticidade no uso do WhatsApp, que vai desde a problemática causada por fake news, até a contribuição do aplicativo para a democratização do acesso à informação e o exercício do pluralismo político. Enquanto na Índia e Brasil há certa desconfiança sobre o predomínio de fake news e a atuação de grupos conspiratórios, em países como o Quênia, Nigéria e Malásia, o uso do aplicativo é analisado como um importante dispositivo de contestaçáo e legitimação da oposição a governos excessivamente longevos, e/ou semiautoritários.

A maioria dos trabalhos encontram evidências empíricas de que o WhatsApp possui impacto sobre a competição eleitoral, variando o seu efeito. Enquanto no caso 
84 | Bruno Schaefer, Tiago Barbosa, Sara Epitácio e Roberta Resende

brasileiro, por exemplo, a estratégia do uso de grupos de WhatsApp foi bem-sucedida para a candidatura de Jair Bolsonaro (PSL), outros partidos e candidatos não tiveram o mesmo sucesso (MACHADO et al., 2019; CHAGAS, MODESTO e MAGALHÃES, 2019). A forma de comunicação política propiciada pelo WhatsApp, dada a natureza privada das conversas realizadas no aplicativo, é significante para o engajamento político, principalmente a partir de enquadramentos partidarizados (YAMAMOTO, KUSHIN e DALISAY, 2018). Em outras palavras, o conteúdo produzido e distribuído a partir do aplicativo tende a favorecer uma ou outra visão de mundo, em desfavor de conhecimentos objetivos acerca da competição eleitoral. Nesse sentido, futuros trabalhos devem se centrar em como a variação dos usos do WhatsApp, por parte de atores políticos, pode favorecer ou desfavorecer a estabilidade democrática, principalmente a partir de comparação entre mais países, lacuna presente na literatura analisada.

- Bruno Marques Schaefer é Mestre e Bacharel em Ciências Sociais pela Universidade Federal do Rio Grande do Sul (UFRGS). Atualmente é Doutorando em Ciência Política pela UFRGS, com bolsa Capes. E-mail: brunomschaefer@gmail.com.

- Tiago Alexandre Leme Barbosa é Mestre em Ciência Politica pela Universidade Federal do Paraná e atualmente é Doutorando em Ciência Política pela UFRGS, com bolsa Capes. E-mail: tiagoalexandrel@gmail.com.

- Sara de Sousa Fernandes Epitácio é Doutora em Ciência Política pela UFRGS. Atualmente é Professora adjunta do curso de Ciência Politica na Unipampa. E-mail: saraepitacio@hotmail.com.

Roberta Carnelos Resende é Doutora em Ciência Política pela UFRGS. Atualmente é Pesquisadora Capes, bolsista de pósdoutorado no programa de pós-graduação em Ciências Sociais da Unisinos.E-mail: roberta_carnelos@yahoo.com.br. 


\section{Referências}

ABDUlLAH, Ali; ELGHOBASHY, Shoaib. The Role of Mass Communication in the Parliamentary Elections' Campaigns in the Kingdom of Bahrain in 2014: A Field Study. Journal of Arts and Social Sciences [JASS], v. 8, n. 2, p. 149-163, 2017

BOURDIEU, Pierre.; CHAMBODERON, Jean-Claude; PASSERON, Jean-Claude. Ofício de Sociólogo: Metodologia de pesquisa na Sociologia. 8. ed. Petrópolis: Editora Vozes, 2015.

BURSZTYN, Victor S.; BIRNBAUM, Larry. Thousands of Small, Constant Rallies: A Large-Scale Analysis of Partisan WhatsApp Groups. In: IEEE/ACM - International Conference on Advances in Social Networks Analysis and Mining, 2019.

CHAGAS, Viktor; MODESTO, Michelle; MAGALHÃES, Dandara. O Brasil vai virar Venezuela: medo, memes e enquadramentos emocionais no WhatsApp pró-Bolsonaro. Esferas, n. 14, p. 1-17, 2019.

CLEMENT, James. WhatsApp: usage penetration in selected countries 2017. Statista, 22 de julho de 2019. Disponível em: <https://www.statista.com/statistics/291540/mobile-internet-user-whatsapp/>. Acesso em: 20 ago. 2019.

CODATO, Adriano; ROEDER, Karolina; SUHURT, Juan. Os três extremos da ideologia: direitistas, centristas e esquerdistas nas eleiçôes municipais. In: BOLOGNESI, Bruno; ROEDER, Karolina; BABIRESKI, Flávia. Quem decide concorrer: a eleição e os vereadores em Curitiba. Curitiba: TREPR; Curitiba: Massimo Editorial, 2018.

COOPER, Harris. Research synthesis and meta-analysis: A step-by-step approach. 3. ed. Thousand Oaks, CA: Sage, 2010.

DACOMBE, Rod. Systematic reviews in political science: what can the approach contribute to political research? Political Studies Review, v. 16, n. 2, p. 148-157, 2017.

DAMANIK, Erond. Middle Class, WhatsApp, and Political Orientation: The Election of North Sumatera Governor, 2018. In: ICSSIS - 1st International Conference on Social Sciences and Interdisciplinary Studies, Atlantis Press, 2019.

DENYER, David; TRANFIELD David. Producing a Systematic Review. In: BUCHANAN, David; BRYMAN, Alan. (Eds.). The SAGE Handbook of Organizational Research Methods. London: Sage Publishing, p. 671-689, 2009.

ESPINOSA, Marcos; VALENZUELA, Carlos; CEDEÑO, Cynthia. ¿Verdad o ficción? El uso político de las redes sociales en la participación política offline en las elecciones presidenciales en Ecuador. Análisis político, v. 30, n. 91, p. 130-145, 2017.

FAROOQ, Gowhar. Politics of Fake News: how WhatsApp became a potent propaganda tool in India. Media Watch, v. 9, n. 1, p. 106-117, 2018.

FIGUEIREDO FILHO, Dalson; PARANHOS, Ranulfo; SILVA JUNIOR, José; ROCHA, Enivaldo; ALVES, Dáfni. O que é, para que serve e como se faz uma meta-análise? Teoria \& Pesquisa, v. 23, p. 205-228, 2014.

FRAHM-ARP, Maria. The political rhetoric in sermons and select social media in three Pentecostal Charismatic Evangelical churches leading up to the 2014 South African election. Journal for the Study of Religion, v. 28, n. 1, p. 114-141, 2015.

FREEDOM HOUSE. Freedom in the world 2018: Kenya. c2019. Disponível em: <https://freedomhouse.org/report/freedom-world/2018/kenya>. Acesso em: 22 nov. 2019 
GIL DE ZÚNIGA, Homero; ARDĖVOL-ABREU, Alberto; CASERO-RIPOLLÉS, Andreu. WhatsApp political discussion, conventional participation and activism: exploring direct, indirect and generational effects. Information, Communication \& Society, v. 1, p. 1-18, 2019.

GLASS, Gene. Primary, secondary and meta-analysis of research. Educational Researcher, v. 5, n. 10, p. 3-8, 1976.

GROLLA, Gabriella; NISHIJIMA, Marislei. A influência da mídia em resultados eleitorais - uma revisão sistemática. Revista Brasileira de Informação Bibliográfica em Ciências Sociais, n. 89, fev. 2019

HALEVA-AMIR, Sharon. Not all about that Facebook: political campaigns and civic engagement in the 2015 elections. Israel Affairs, v. 22, n. 3-4, p. 711-726, 2016.

HASAN, Kashif; JOHRI, Sanjay. Political campaign in the era of internet: politics of like, comment and share in bihar election 2015. International Journal of Innovative, Research \& Advanced Studies, v. 4, n. 7, p. 170-175, jul. 2017.

HAVERLAND, Markus. Conceiving and designing political science research: Perspectives from Europe. European political science, v. 9, n. 4, p. 488-494, 2010.

HAVERLAND, Markus; YANOW, Dvora. A hitchhiker's guide to the public administration research universe: surviving conversations on methodologies and methods. Public Administration Review, v. 72, n. 3, p. 401-408, 2012.

HENRIKSEN, Dorte. The rise in co-authorship in the social sciences (1980-2013). Scientometrics, v. 107, n. 2, p. 455-476, 2016.

INYANG, Etiido. Spatiotemporal activism and the 2015 presidential elections in Nigeria: a critical analysis of social media graphics of the "Buhari Change" campaign. South African Journal of Art History, v. 31, n. 2, p. 34-48, 2016.

KIRCHHEIMER, Otto. The transformation of the Western European party systems. In: LAPALOMBARA, Joseph; WEINER, Myron (Orgs.). Political parties and political development. New Jersey: Princeton University Press, 1966. p. 177-200.

KITCHENHAM, Barbara. Procedures for performing systematic reviews Technical Report TR/SE0401. Keele: Keele University and NICTA, 2004.

KRAUSE, Silvana; SCHAEFER, Bruno; BARBOSA, Tiago; CORREA, Carolina; TELLES, Helcimara. Die brasilianische Präsidentschaftswahl 2018: Ein neues Paradigma der Finanzierung, Anti-Politik und Soziale Netzwerke. Zeitschrift für Parteienwissenschaft, v. 25, p. 94-110, 2019.

MACHADO, Caio; KIRA, Beatriz; NARAYANAN, Vidya; KOLLANYI, Bence; HOWARD, Philip. A Study of Misinformation in WhatsApp groups with a focus on the Brazilian Presidential Elections. In: Companion Proceedings of the 2019 World Wide Web Conference, ACM, p. 1013-1019, 2019.

MAHAPATRA, Sangeeta; PLAGEMANN, Johannes. Polarisation and politicisation: the social media strategies of Indian political parties. GIGA Focus [Asia], n. 3, mar. 2019. Disponível em: $<$ https://www.giga-hamburg.de/en/publication/polarisation-and-politicisation-the-social-mediastrategies-of-indian-political-parties>. Acesso em: 20 out. 2019.

MONT'ALVERNE, Camila; MITOZO, Isabele. Muito além da mamadeira erótica: As notícias compartilhadas nas redes de apoio a presidenciáveis em grupos de WhatsApp, nas eleiçóes brasileiras de 2018. In: $8^{\circ}$ Compolítica: Política e Comunicação Pós-Eleiçôes no Brasil, Brasília, 2019. 
MORAH, Doris; UZOCHUKWU, Chinwe. Nigeria's Social Media Culture Exploring Civic Participation of Youths in the 2015 Presidential Election. International Journal of Advance Study and Research Work, v. 2, n. 1, jan. 2019

NARAYANAN, Vidya; KOLLANYI, Bence; HAJELA, Ruchi; BARTHWAL, Ankita; MARCHAL, Nahema; HOWARD, Philip. News and Information over Facebook and WhatsApp during the Indian Election Campaign. The Computational Propaganda Project, 13 mar. 2019. Disponível em: <https://comprop.oii.ox.ac.uk/research/india-election-memo/>. Acesso em: 20 out. 2019.

NICOLAU, Jairo. O impacto do fundo eleitoral nas campanhas para deputado. Nexo, 30 abr. 2019. Disponível em: <https:/www.nexojornal.com.br/ensaio/2019/O-impacto-do-fundo-eleitoral-nascampanhas-para-deputado>. Acesso em: 23 ago. 2019.

NIZAH, Mohd; BAKAR, Afi. WhatsApp Election in Malaysia: Assessing the Impact of Instant Messaging on Malaysia's 14th General Election. International Journal of Academic Research in Business and Social Sciences, v. 9, n. 3, p. 132-146, 2019.

OMANGA, Duncan. WhatsApp as 'digital publics': the Nakuru Analysts and the evolution of participation in county governance in Kenya. Journal of Eastern African Studies, v. 13, n. 1, p. 175$191,2019$.

ORTEGA, Jose; AGUILLO, Isidro. Mapping world-class universities on the web. Information Processing and Management, v. 45, n. 2, p. 272-279, 2009.

OYEBODE, Oluwabunmi; ADEGOJU, Adeyemi. Appraisal Resources in Select WhatsApp Political Broadcast Messages in the 2015 Presidential Election Campaign in Nigeria. Journal of Pan African Studies, v. 10, n. 10, p. 29-48, 2017.

PADILHA, Maria; RAMOS, Flávia; BORENSTEIN, Miriam; MARTINS, Cleusa. A responsabilidade do pesquisador ou sobre o que dizemos acerca da ética em pesquisa. Texto \& Contexto - Enfermagem, v. 14, n. 1, p. 96-105, 2005.

PETTICREW, Mark. Systematic Reviews from Astronomy to Zoology: Myths and Misconceptions. British Medical Journal, v. 322, p. 98-101, 2001.

PETTICREW, Mark; ROBERTS, Helen. Systematic Reviews in the Social Sciences: A Practical Guide. Oxford: Blackwell, 2006.

PRANAWA, Sigit; HUMSONA, Rahesli. Social Media in Political Marketing: A Study of TemanAhok. KnE Social Sciences, p. 236-243, 2017.

RESENDE, Gustavo; MELO, Philipe; REIS, Julio; VASCONCELOS, Marisa; ALMEIDA, Jussara; BENEVENUTO, Fabrício. Analyzing Textual (Mis) Information Shared in WhatsApp Groups. In: WebSci'19 - Proceedings of the 10th ACM Conference on Web Science Pages, Boston, 2019.

SAMPAIO, Daniel; FIGUEIREDO FILHO, Dalson. Como o dinheiro influência as eleiçóes municipais no Brasil: Uma revisão sistemática. Revista Brasileira de Informação Bibliográfica em Ciências Sociais, v. 1, n. 88, p. 1-25, 2019.

SÁNCHEZ, Álvaro; SÁNCHEZ, María; RUIZ, Eliza; SÁNCHEZ, Milton; DUEÑAS, Víctor; LAVÍN, José. Whatsapp and Facebook as a new political agora? In: ICEDEG - 2018 International Conference on e Democracy \& eGovernment, IEEE, 2018. p. 366-370.

SANTOS, Fabiano; TANSCHEIT, Talita. Quando velhos atores saem de cena: a ascensão da nova direita política no Brasil. Colombia Internacional, n. 99, p. 151-186, 2019. 
88 | Bruno Schaefer, Tiago Barbosa, Sara Epitácio e Roberta Resende

SÁTYRO, Natália; REIS, Bruno. Reflexôes sobre a produção de inferências indutivas válidas em ciências sociais. Revista Teoria \& Sociedade, n. 22.2, p. 13-39, jul./dez. 2014.

SETEOLU, Bamidele. What will Election be without the Media: An Appraisal of the Media and 2015 Presidential Elections in Nigeria. Journalism and Mass Communication, v. 7, n. 2, p. 78-89, 2017.

SINGH, Manish. WhatsApp reaches 400 million users in India, its biggest market. Techcrunch, 26 jul. 2019. Disponível em: <https://techcrunch.com/2019/07/26/whatsapp-india-users-400million/>. Acesso em: 24 ago. 2019.

SUMARTIAS, Suwandi. Utilization of Whatsapp as a political communication channel politicians padang city. In: ICOSOP - 2nd International Conference on Social and Political Development, Atlantis Press, 2017.

TAPSELL, Ross. The Smartphone as the "Weapon of the Weak": Assessing the Role of Communication Technologies in Malaysia's Regime Change. Journal of Current Southeast Asian Affairs, v. 37, n. 3, p. 9-29, 2018.

WHATSAPP. Stopping Abuse: How WhatsApp Fights Bulk Messaging and Automated Behavior. Whatsapp, 2019. Disponível em:

<https://www.whatsapp.com/safety/WA_StoppingAbuse_Whitepaper_020418_Update.pdf>. Acesso em: 29 ago. 2019.

YAMAMOTO, Masahiro; KUSHIN, Matthew; DALISAY, Francis. How informed are messaging app users about politics? A linkage of messaging app use and political knowledge and participation. Telematics and Informatics, v. 35, n. 8, p. 2376-2386, 2018. 